\title{
RAPID MOVEMENT OF A B-CHROMOSOME FREQUENCY CLINE IN MYRMELEOTETTIX MACULATUS (ORTHOPTERA: ACRIDIDAE)
}

\author{
M. W. SHAW* \\ School of Biological Sciences, University of East Anglia, Norwich NR4 7TJ, U.K.
}

Received 8.vii.82

\section{SUMMARY}

The distribution of Myrmeleotettix maculatus B-chromosomes in part of East Anglia has been mapped twice, at an interval of 10 years. A cline in Bchromosome frequency is moving forward at c. $300 \mathrm{~m} \mathrm{y}^{-1}$ and is about $3-5 \mathrm{~km}$ wide.

If the cline represents a simple wave of advance, the standard deviation in position of offspring around their parent must be of the order of $1000 \mathrm{~m} \mathrm{y}^{-1 / 2}$. However, measurements suggest that this figure cannot be more than about $50 \mathrm{~m} \mathrm{y}^{-1 / 2}$. Climatic change is also inadequate to explain the movement.

It is therefore suggested that geneflow through extinction and recolonisation of small populations may be more important than diffusion of individuals in genetically structuring this species.

\section{INTRODUCTION}

Clines have been keenly studied because of the light they can throw on the processes of adaptation and geneflow in spatially structured populations (Endler, 1977; May, Endler and McMurtrie, 1975; Barton and Hewitt, 1981). Despite this work, there have been few quantitative studies of moving clines. Most of the studies that have been made concern responses to human-made environmental changes. Two examples are the increase and more recently the decline in frequency of melanic forms of the moth $B$. betularia (e.g., Lees, 1981), and the spread of Warfarin resistance in rats (Greaves and Rennison, 1973). An example of a change occurring in the wild, without an obvious environmental cause, is the spread of the yellow morph of the Bananaquit (Coeroba flaveola: aves) on Granada in the W. Indies (Wunderle, 1981). However, well characterised examples of the spread of genetic change remain rare.

The theory of the spread of a selectively advantageous allele was first studied by Fisher (1937) for a 1-dimensional habitat. It has been elaborated by, for example, Slatkin (1976). This work related the rate of spread of an advantageous allele appearing initially at one location, to the mean square dispersal of offspring around the parent's birthplace and the selective advantage of the allele, $s$. By dimensional analysis it is easy to see that $v$, the linear rate of spread, must be $\kappa \sqrt{\sigma^{2} s}$, where $\kappa$ is a constant. This is true in both 1 and 2 dimensions. Both Slatkin and Fisher, using 1dimensional stepping-stone and continuous models respectively, obtained $\kappa \sim 1$ or less. The two dimensional case needs investigation. It is clear that the theory for 1 dimension will apply, apart from relatively small changes

* Present address: Department of Biology, University of York, Heslington, York YO1 5DD. 
in $\kappa$, when the spread of the genetic variant has progressed sufficiently far that the radius of curvature of the cline is much greater than $\sigma$. However, no proper theoretical treatment has been published. Simulations were made by Slatkin and Charlesworth (1978) but they felt that they had accumulated too little data to come to any definite conclusions. Since, on the whole, communication between demes a given distance apart is reduced in twodimensional habitats (e.g., Kimura and Weiss, 1962), $\kappa$ is unlikely to be greater in the two-dimensional case than in the one-dimensional. Thus if $s, \sigma^{2}$ and $v$ can be measured, this theory provides a fairly robust probe of how genetic change spreads in a population. This has considerable implications for the extent to which evolution can produce adaptation, and for theories of speciation, since it defines the timescale over which groups are adaptively isolated.

One case in which all the elements needed for a synthesis have been published is that of Warfarin resistance in rats. Here, however, the rate of spread of resistance is far too high to be accounted for by the available estimates of $\sigma^{2}$. This is probably due to the population structure in rats, which makes $\sigma^{2}$, as measured, quite inadequate for assessing longer-range dispersal (Hartley and Bishop, 1979). Clearly, further examples in other organisms are desirable.

I report here on what seems to be an advancing cline in B-chromosome frequency in a grasshopper, Myrmeleotettix maculatus (Thunb.). (Jones, 1975 provides a comprehensive review of B-chromosome biology). $M$. maculatus is a widespread palearctic grasshopper species which has a B-chromosome present at intermediate frequency in many populations in Southern Britain, but absent from continental Europe (Hewitt, 1973). (A single population with a very low frequency is known on Öland, off Sweden. See Ramel, 1981). The B has been intensively studied by Hewitt and coworkers. It is a medium-sized metacentric element, easy to distinguish from all other members of the chromosome complement during both mitosis and meiosis. It is maintained in populations where it is present at a frequency of about 50 per cent, mostly in karyotypes with a single $\mathrm{B}$, by a balance between meiotic loss in the male, meiotic drive in the female (Hewitt, $1976,1973)$ and some uncharacterised severe disadvantage of the $2 B$ karyotypes (Shaw, 1981). The fitness of grasshoppers with $1 \mathrm{~B}$ is about the same as those with none (Shaw, 1981).

The distribution of the B over most of Britain was mapped during the late 1960s and the early 1970s. Intensive sampling was carried out in East Anglia by Hewitt and Brown (1970) and Robinson and Hewitt (1976). Part of this area was remapped during the study reported here. The original aim was simply to refine the earlier work, but comparison of the two sets of data showed that a definite change in the distribution had occurred. Climatic data and measurements of dispersal are available, so a rough comparison of the observations with theoretical predictions is possible.

\section{METHODS}

Sites where $M$. maculatus lived in reasonable numbers were found in three ways: by examining areas marked as rough ground on Ordnance Survey maps covering the region of interest; by checking likely habitats such as railway cuttings; and by noting areas of heath visible from roads 
in the area. Male grasshoppers were captured individually in Ragge tubes while walking back and forth over a site. Although only males were scored, male and female $B$ frequencies are equal as far as can be determined from other studies (data are summarised in Shaw, 1981). Testes were dissected directly into fresh Carnoys fixative (3:1 ethanol:acetic acid) and stored for two days or more. Karyotypes were determined by examining meiotic divisions in two or three testis follicles stained in propionic orcein.

\section{RESUlts}

\section{(i) The cline movement}

Fig. 1 is a map of the region studied showing the major features relevant to the distribution of $M$. maculatus. Suitable habitats are rarer in the better farmland to the East and the marshy ground in the North-west corner. However, the vegetation and soil types at those sites where $M$. maculatus is found are similar throughout the area (Robinson, 1973).

Large scale mapping in E. Anglia (Hewitt and Brown, 1970) identified the present study area as the region in which $B$-frequencies changed from c. 50 per cent to zero. The detailed observations made during the period 1967 to 1972 (Hewitt and Brown 1970, Robinson and Hewitt 1976) are summarised in fig. 2 as pie diagrams plotted on a map of the region. The data gathered during $1979-80$ are shown in the same way in fig. 3. To make comparison of the general features of the two distribution maps

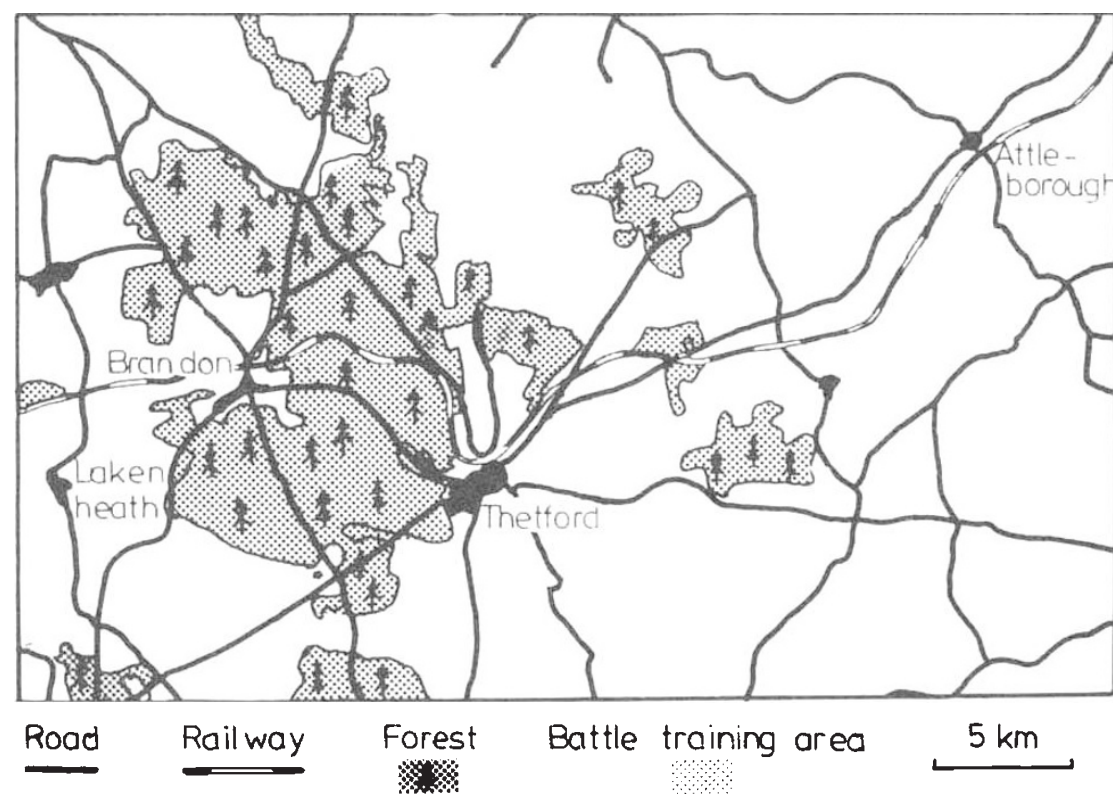

FIG. 1. This map shows some geographic features of the area of study. Where land is farmed or forested, populations of $M$. maculatus are restricted to occasional suitable patches of heath. Where heath does not occur naturally, as in the East or North-west of the region shown, populations are also rare. In the Ministry of Defence battle area near Thetford populations of a range of sizes are particularly common, as the region is not intensively farmed. 


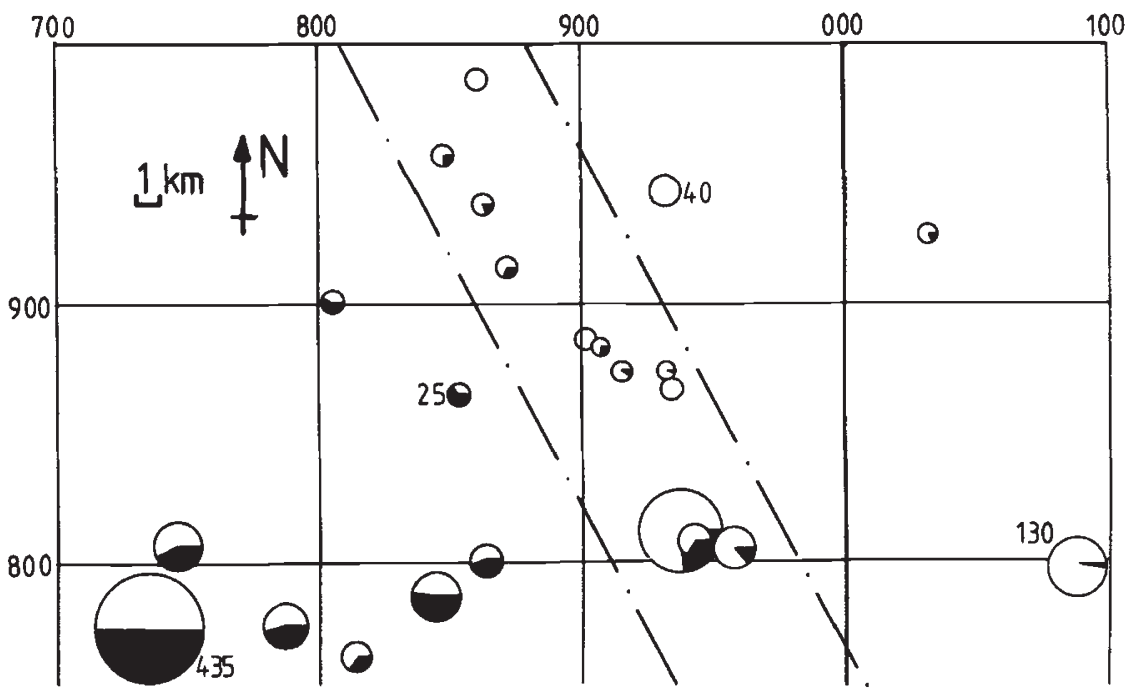

FIG. 2. A map of the frequency data within the study area, for 1967-72. Each pie-diagram has an area proportional to sample size; the shaded portion represents the proportion of the sample with one or more B-chromosomes. The sizes of three samples are marked next to the relevant pie-charts so as to set a scale. A complete listing of the data used to construct figs. 2 and 3 appears in Shaw (1981).

National Grid $10 \mathrm{~km}$ squares are superimposed on the map. The left-hand threequarters of the region lie in $100 \mathrm{~km}$ square TL; the right-hand quarter in $100 \mathrm{~km}$ square TM. The "zones" mentioned in the text are separated by the dash-dotted lines.

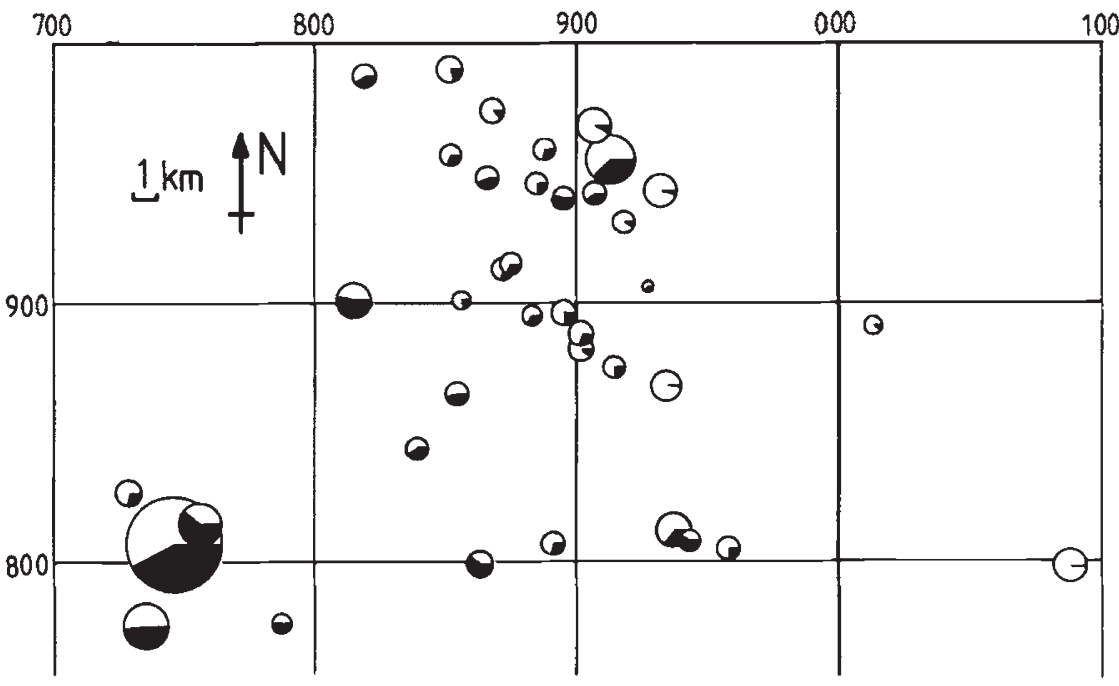

FIG. 3. As fig. 2, but covering 1979-80.

easier, figs. 4 and 5 show contour maps of B-frequency prepared from the data of figs. 2 and 3 using the package GPCP at the University of Manchester computing centre. Note that these contour maps pass exactly through all the data points, so that some of the fluctuations apparent are due to sampling 


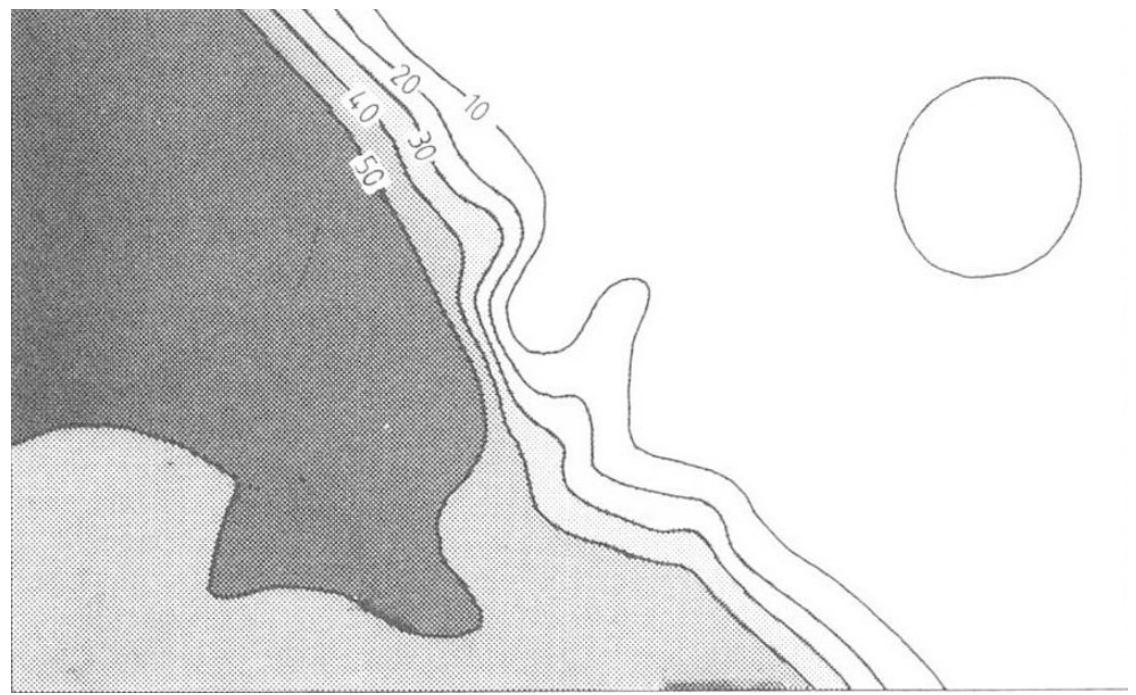

FIG. 4. As fig. 2, but the contours of a smooth surface passing through the sample points have been drawn on instead of pie-diagrams. The figures indicate the percentage of animals with one or more B's, at the position of the contour.

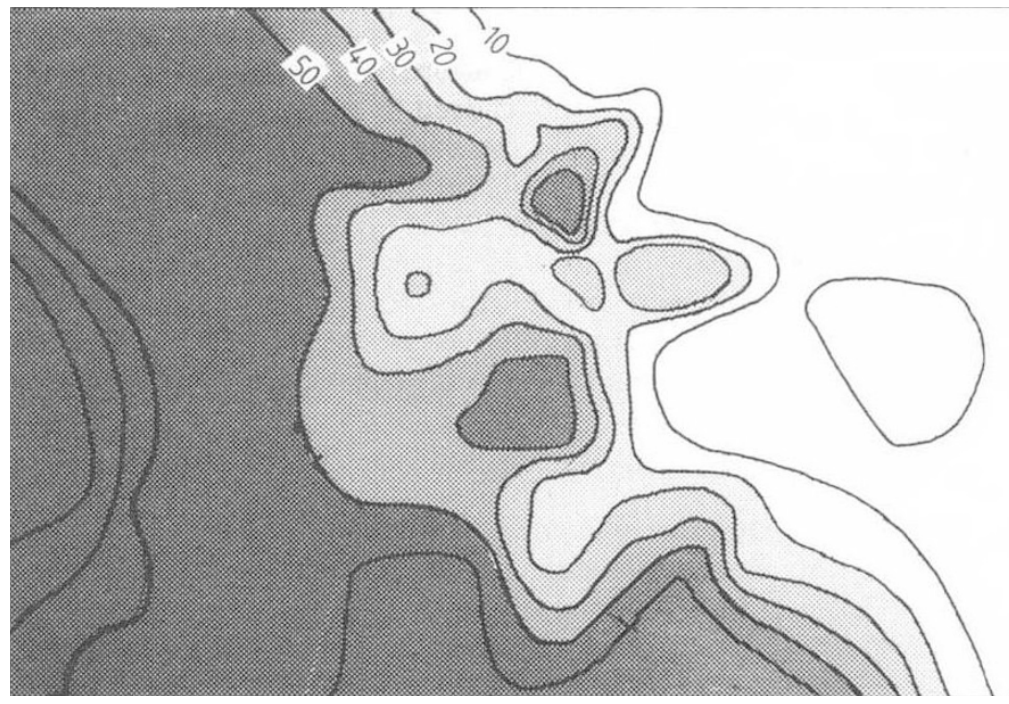

FIG. 5. As fig. 4, but covering 1979-80.

error. The overall patterns, however, reflect real features of the distribution. (For example, no B's have been found in sites east of the area shown in the figures.)

At both periods the major feature is a cline running roughly Northwest to southeast, roughly $5 \mathrm{~km}$ wide. If anything the cline is broader during the second period than during the first. The more obvious fluctuations in 
the overall cline during the later period are almost certainly attributable simply to more intensive sampling. However, the most striking difference between the two maps is that the cline seems to have moved a few $\mathrm{km}$ northeastwards during the interval between them.

This visual impression of movement needs to be tested statistically. This can be done as follows. First, using the 1965-72 map the region is divided into three zones: one where the proportion of animals with B's is consistently high, one where it is consistently low, and a transition zone between them (see fig. 2). Then, within each zone, at all sites where data are available in both periods, contingency $\chi^{2}$ 's are calculated, as if to test for a change

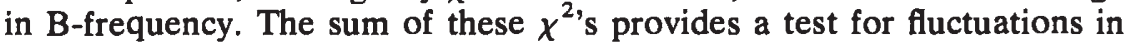
B-frequency at all sites considered together, greater than can be attributed to sampling error. The square roots of the individual $\chi_{1}^{2}$ values, whe $n$ given a sign to correspond to an increase or a decrease of B-frequency, should each be distributed as a normal deviate of mean zero and variance 1 if only sampling changes have occurred. The sum of $n$ of these deviates should be normal with variance $n$ and mean 0 if there has been no tendency for change to occur in a single direction at all the sites. This provides a conservative test for movement in the cline, as opposite to fluctuation (see e.g., Snedecor and Cochran, 1963).

Table 1 is a summary of the calculations involved. It is clear that only in the transition zone have B-frequencies changed, and that there they have risen consistently. Elsewhere, neither significant fluctuation, nor consistent change has occurred. (In calculating the $\chi^{2}$ values sites where no B's were originally seen have been omitted, since no change other than an increase is possible.) In a number of cases, particularly in the transition zone, collections have been compared that were made up to a few hundred metres apart. This does not invalidate the conclusion that the cline has moved in the last ten years, since the probability that, by chance alone, all sites chosen on the second occasion would be higher in frequency than those chosen on the first is very small; in fact, using a sign test on all eleven observations, this probability is 0.001 . Furthermore, where the earlier site differs from the later, the later is usually east of the earlier, so that any bias should tend to produce a consistent change opposite to that observed.

\section{(ii) Dispersal}

Some measure of geneflow is needed to interpret these results. Two complementary estimates are available for $M$. maculatus. First, Aikman and Hewitt (1972), using an artificial population living in a uniform and benign habitat, measured the average dispersal of grasshoppers during the first four instars-that is, roughly from hatching to mating. Including some initial density dependant dispersal, they obtained an estimate of roughly $7 \mathrm{~m} \mathrm{gen}^{-1 / 2}$. A second, independent, albeit crude, estimate can be obtained from work carried out at the large area of heathland at Lakenheath Warren, Suffolk, during 1979 and 1980.

Collections of male grasshoppers were made on several occasions throughout both summers at a number of locations within the site, from $20 \mathrm{~m}$ to $100 \mathrm{~m}$ apart, and the B-frequencies in these samples determined. A full analysis of these data appears in Shaw (1981). Here, it is only necessary to note that there was no site $\times$ date of sampling interaction with 
TABLE 1

Statistical comparison of sites in the three regions defined in fig. 2. The null hypothesis is that only sampling error contributes to differences between years

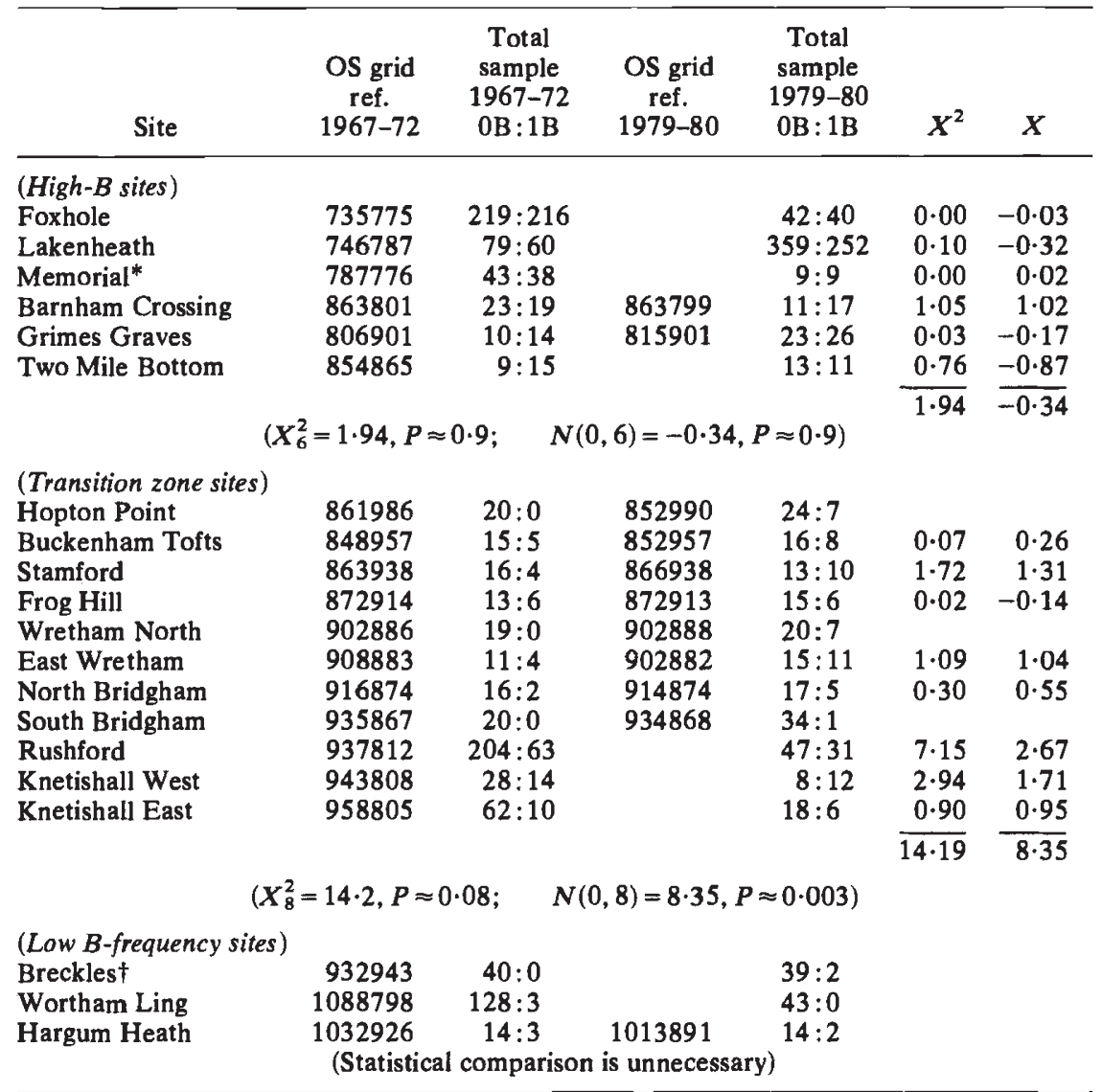

* Including 20 individuals collected in 1965.

$\dagger$ Breckles was the site of a transplant experiment in 1972; see text.

respect to B-frequencies, and that sample sizes at each site were comparable on different dates. Thus the data can legitimately be pooled over dates to look for intersite differences. These pooled data are set out and analysed in table 2. Overall, it is likely $(P=0.06)$ that the sites differ; in particular, site 1 differs from the rest $(P=0.007$, after allowing for the seven such comparisons possible in the data).

This difference may be due to drift or to a selective difference between the sites. Site 1 is not noticeably differentiated by topography or vegetation from the other sites, so drift is an attractive explanation. In this case the $50 \mathrm{~m}$ to the nearest sites also scored would represent a few dispersal distances. This is consistent with Aikman and Hewitt's (1972) measurements. If, however, there are selective differences between the sites, the scalings of May, Endler and McMurtrie (1975) may be used to get a feel for the range of possible dispersal figures. 
TABLE 2

Frequencies of karyotypes found at Lakenheath during 1979 and 1980. All data at each collecting site over this period have been pooled. The seven collecting sites are shown in fig. 6

\begin{tabular}{ccccccc}
\hline Site & OB & 1B & 2B & 3B & Total & $\begin{array}{c}\text { Average B's } \\
\text { per animal }\end{array}$ \\
\hline 1 & 39 & 36 & 14 & 2 & 91 & 0.77 \\
2 & 38 & 14 & 4 & & 56 & 0.39 \\
3 & 21 & 12 & 5 & 38 & 0.58 \\
4 & 63 & 30 & 6 & 99 & 0.42 \\
5 & 56 & 31 & 6 & 94 & 0.46 \\
6 & 66 & 30 & 9 & 105 & 0.46 \\
7 & 14 & 14 & 3 & 31 & 0.65 \\
& \multicolumn{7}{c}{ Between sites $X_{12}^{2}=20.4, P \approx 0.06$} \\
\end{tabular}

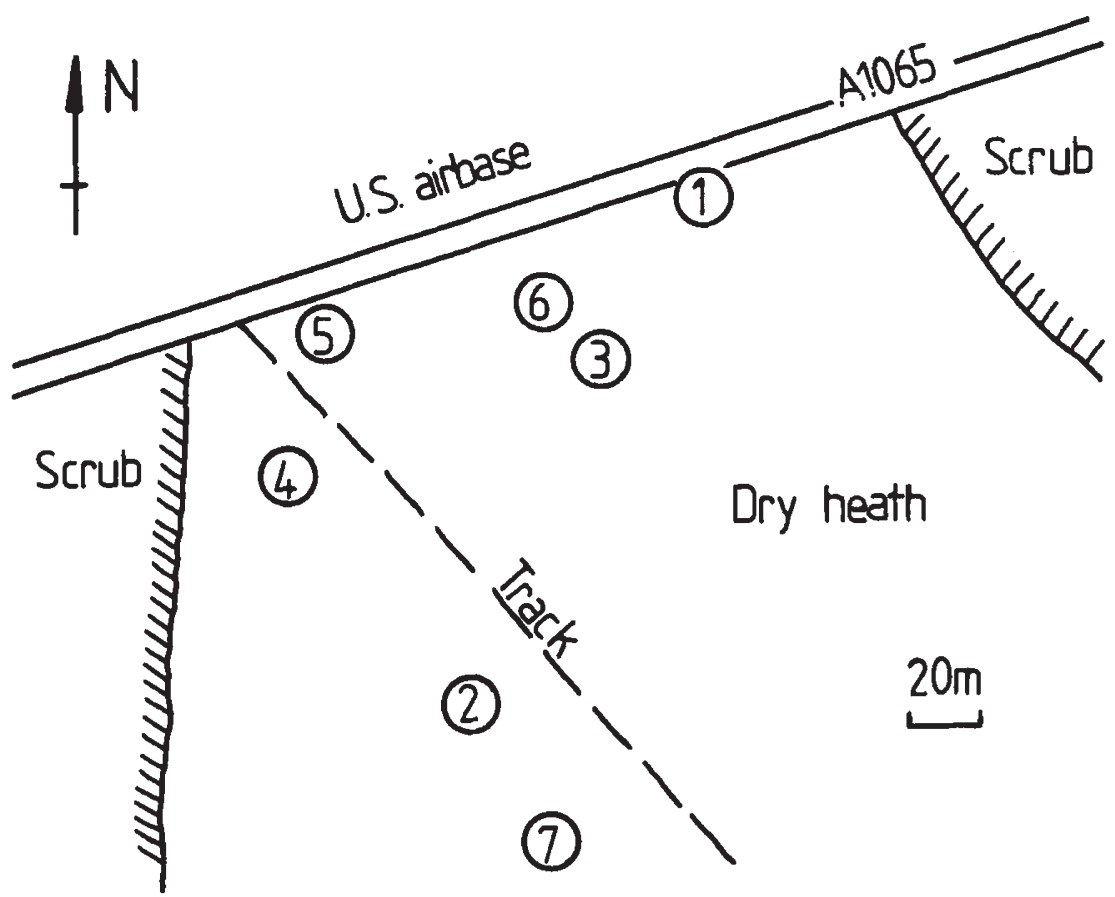

FIG. 6. Sketch map of Lakenheath Warren, showing the sites where repeated collections were made in 1979 and 1980.

First, we need to define four symbols: $w$, the width of the clinemeasured as, e.g., the inverse of the maximum slope; $\Delta$, the width of an environmental gradient underlying the difference between sites; $s$, the selective difference between sites; and $\sigma^{2}$, the dispersal variance used in the introduction to this paper. Now, the highest B-frequency ever observed is around 1B/animal (Shaw, 1981), so the frequency at site 1 cannot reasonably be supposed to be much lower than the maximum frequency in the gradient along which it occurs: that is, $w$ must be $50-100 \mathrm{~m}$. 
Suppose site 1 is separated from its surroundings by a sharp environmental gradient, an ecotone, so that $\Delta \ll w$. Then (May et al., 1975) $w \sim$ $\sqrt{\sigma^{2} / s}$, so $\sigma \sim w s^{1 / 2}$; if $s$ were $\sim 10$ per cent, $\sigma \sim 5-10 \mathrm{mgen}^{-1 / 2}$. Any plausible $s$ will then yield $\sigma$ less than about $50 \mathrm{mgen}^{-1 / 2}$. If, instead, $\Delta$ were comparable with $w$, May et al. calculate the scaling $w \sim\left(\Delta \sigma^{2} / s\right)^{1 / 3}$; hence $\sigma\left(w^{3} s / \Delta\right)^{1 / 2}$. Hence $\sigma \sim 10^{3}(s / \Delta)^{1 / 2}$ at most. However, $s / \Delta$ must be «1 since by hypothesis $\Delta \sim w$, and if $\Delta$ is small we approximate the ecotone model. Thus $s / \Delta$ cannot be much greater than $0 \cdot 1 / 10$ at the most; so a maximum estimate of $\sigma$ is of order $100 \mathrm{~m} \mathrm{gen}^{-1 / 2}$.

On the whole, therefore, it seems fair to use $50 \mathrm{~m} \mathrm{gen}^{-1 / 2}$ as an upper estimate of plausible dispersal. This is in reasonable agreement with Aikman and Hewitt's point estimate of $7 \mathrm{mgen}^{-1 / 2}$. It is the upper limit that is important in considering the movement of the cline.

\section{Discussion}

The observations introduced so far suggest that populations $50 \mathrm{~m}$ or so apart are not tightly coupled by dispersal. On the other hand, consistent changes in B-frequency within a zone c. $20 \mathrm{~km}$ by $5 \mathrm{~km}$ have been observed. The first observation suggests that B-frequencies in populations separated by about $1 \mathrm{~km}$ (at most) should evolve independently except over extremely long timescales. Therefore the changes in the transition zone must have been independent at each site: their consistency must be ascribed to some cause other than dispersal, such as an environmental change.

Any possible cause must satisfy a number of criteria arising from theoretical models of the evolution of B-frequency in populations of $M$. maculatus (Shaw, 1981). These suggest, first, that changes in B-frequency occur fairly smoothly as the controlling parameters of the equilibriummeiotic drive and selection on 1B grasshoppers-change. Second, decrease in B-frequency from a fluctuation above the equilibrium is faster than the rise to equilibrium from below. Since the B-frequency in the west of the region is remarkably constant over the period of these observations, a general change in environmental conditions can only explain the data if some threshold phenomenon for one or several of the parameters controlling the B-frequency is also assumed. There is in any case no firm evidence for an environmental change in the region over the period considered. Changes in pesticide residue concentration, predator numbers, etc., cannot be assessed. The only environmental factor for which there is good evidence is the weather.

Climatic data were obtained, via the Meteorological Office, from five weather stations in and around the study area. Three variables were examined: mean daily maximum temperature during June, July and August; total sunshine hours during these three months; and rainfall during May and June. The first two were chosen as variables of obvious importance for a basking insect whose behaviour is strongly dependent on temperature. Rainfall was included because Robinson (1973) showed that this was a key determinant of the proportion of nymphs surviving to adulthood. Differences between the average values of these variables at the different stations are slight compared with year-to-year variation and show no obvious spatial pattern. Further, the correlations between the measurements made at different stations on sunshine and temperature are all more than 0.98 , so 
that one station may be taken as a proxy for all. The correlations between stations for rainfall are somewhat lower at about 0.8 .

No trend is discernable in the time series for daily maximum temperature or sunshine. Nor is there any trend in the average May and June rainfall at any station. Only the two drought years 1975 and 1976, with exceptionally hot and sunny weather, require further comment. Suppose these two years raised the B-frequency in the transition zone very high. After three or four years it had still not relaxed to its former level, so the frequency immediately after the period of high temperatures must have been substantially higher than that now observed. In particular, this level must have been higher than that now seen in the westerly "high-B" area. Yet in this area, also subject to the hot weather, the B-frequency was apparently unchanged (table 1). Thus, it is hard to ascribe the changes seen in the "transition zone" either to the exceptional weather in $1975 / 6$, or to any medium-term trend in the climate.

Two further observations bear in opposite directions on the hypothesis that climate controls the cline. First, the population established at Norwich

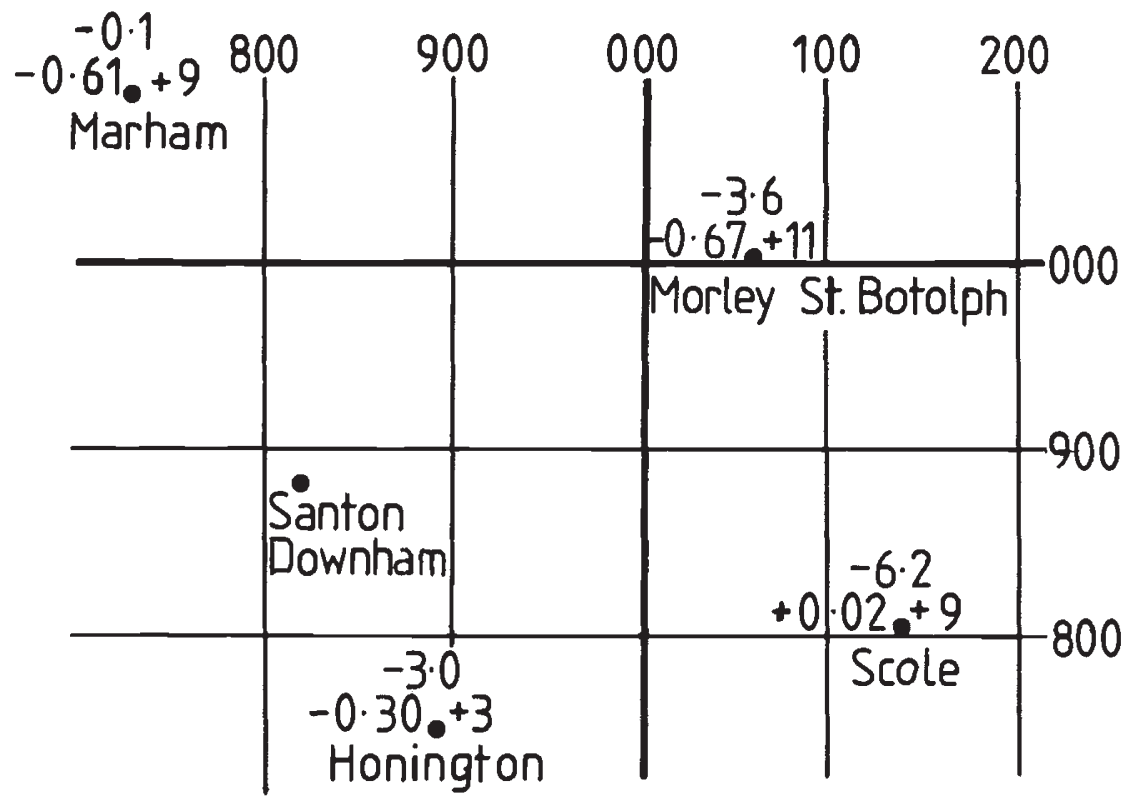

FIG. 7. The positions of weather stations in and around the study region. The left-hand figure at each site is the mean deviation of the average daily maximum temperature during June, July and August from that at Santon Downham. The right-hand figure is the average deviation of the total sunshine received during those months from that received at Santon Downham. The top figure is the average deviation of the rainfall during May and June from that at Santon Downham. At Santon Downham the three variables have average values over $1960-80$ of $20.87^{\circ} \mathrm{C} ; 182 \mathrm{~h}$; and $48 \mathrm{~mm}$ respectively. 


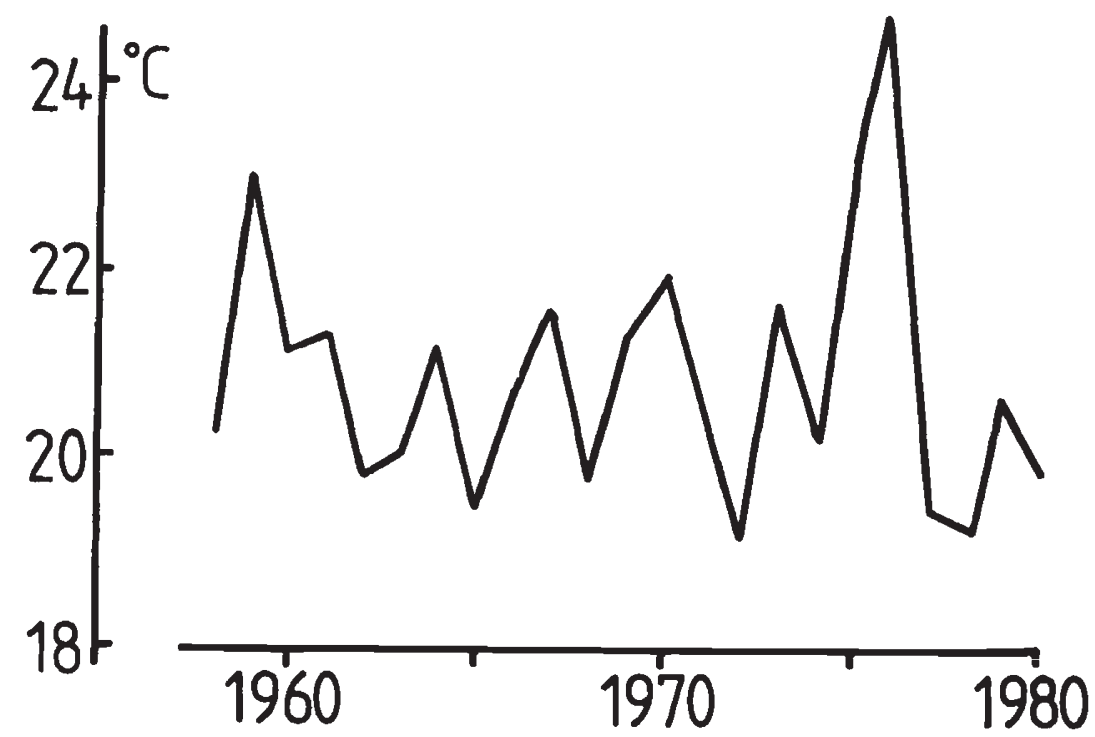

FIG. 8. Time-series of average daily maximum temperature over June, July and August, at Santon Downham. The slope of a regression on time is $-0.007^{\circ} \mathrm{C} \mathrm{y}^{-1}$ but is not statistically significant.

by $\mathrm{Dr}$ G. M. Hewitt during the dispersal experiment flourished for 4 years or so, until the area of the experiment was built over. Other populations in this area do not possess B's (Hewitt and Brown 1970), but this population came from Lakenheath and possessed, presumably, an initial B-frequency of about 50 per cent. When it was known to be threatened, the majority of the grasshoppers were collected and karyotyped. The B-frequency was still high. (Hewitt, personal communication). The mathematical models detailed in Shaw (1981), chapter 3, suggest that after four years a very substantial fall in the B-frequency should have been observed if the equilibrium was actually zero. This suggests that no climatic influence prevents the $\mathrm{B}$ from persisting in populations much further east than is actually observed. On the other hand, in 1973 Drs G. M. Hewitt and P. M. Robinson eliminated as far as possible the nymph population at the isolated site of Breckles Heath (OS 932943 TL) by repeated collections. They then replaced it with animals taken from Thetford Heath (OS 844787TL) where about 50 per cent of individuals carry B's (Robinson 1973). Yet, in 1979-80, the B-frequency at Breckles was only about 5 per cent (table 1). However, this decline has many possible interpretations. For example, the effective inocculum of Thetford grasshoppers may have been smaller than intended and by chance, carried few B-chromosomes.

If we suppose that environmental change is not the cause of the cline movement, this movement must represent a Fisherian advancing wave, with the B-chromosome steadily colonizing more and more of the U.K. M. maculatus populations. However, the theory of this process makes order of magnitude predictions about the relation between dispersal, the 
width of the cline, and its rate of movement, which are not compatible with the data.

Suppose, for the present, a rather strong effective selective differential on the $\mathrm{B}$, allowing for both meiotic drive and selection, of $0.1 \mathrm{gen}^{-1}$, and the upper limit on plausible dispersal deduced earlier of $2500 \mathrm{~m}^{2}$ gen $^{-1}$. Then Fisher's theory yields a speed $\sim \sqrt{\sigma^{2} s} \approx 15 \mathrm{~m} \mathrm{y}^{-1}$, and a width $\sim \sqrt{\sigma^{2} / s} \approx 150 \mathrm{~m}$. Both are far smaller than observed. Alternatively, taking a speed of $\sim 300 \mathrm{~m} \mathrm{y}^{-1}$, and a width $\sim 3000 \mathrm{~m}$, and solving for $s$ and $\sigma^{2}$ we obtain $s \sim 0.1$ gen $^{-1}$, which is reasonable, and $\sigma^{2} \sim 10^{6} \mathrm{~m}^{2}$ gen $^{-1} \equiv \sigma \sim$ $10^{3} \mathrm{mgen}^{-1 / 2}$, which is emphatically not reasonable, even if all $M$. maculatus were to disperse to the full extent of their vagility.

Thus, we apparently reach the unpalatable conclusion that we must ascribe the cline movement to some unknown, and now perhaps unknowable, force-an hypothesis with no predictive power, and quite useless for generalisation. Before going this far, it is worth considering the assumptions underlying the scalings used above. Variations in the detailed formulation (Hadeler, 1975) or structure (Slatkin, 1976) of the model do not alter scalings derived from Fisher's model: if anything, the constants become substantially less than one, and so make the theory seem still less adequate. However, all the reformulations contain the assumption that gene-flow is proportional to numbers of individual dispersing; or, to put it another way, that individuals disperse between established populations and have similar fitnesses in the population from which they come and to which they go.

However, if extinction and recolonization of small populations is important in the ecology of $M$. maculatus, an alternative view of the geneflow involved in the cline is possible. Consider a mated female leaving a favourable habitat-for whatever reason-and therefore searching for a new place to live. Under these circumstances, she is likely to move further and faster than under the benign conditions of Aikman and Hewitt's (1972) experiment, or in the extensive favourable habitat at Lakenheath. If she finds an inhabited site, her genes might represent at most a few per cent of the next generation, perhaps substantially less than a comparable "native" individual if there is competition for laying sites or succulent food resources. However, in a newly appearing site, or a site in which chance extinction has occurred, her reproductive success could be enormous: her and her mate's genes might represent 100 per cent of those present in a fairsized population a few years later. In effect, a recolonization event can amplify geneflow by a factor of hundreds or even thousands (although the extinction or founding of large populations is likely to be much rarer than that of small ones). Thus, the geographic rate of advance of a selectively favoured variant could be far faster than when extinction and recolonization are unimportant. One would also expect a spotty, uneven, edge to the cline, and that the cline would be wider than otherwise expected: both of these are observed in the present example.

The importance of extinction-recolonization processes in population dynamics has often been neglected. However, a number of studies suggest that they may be important in a wide variety of organisms, and explain a number of different phenomena. For example, Carter and Prince (1981) use a model incorporating these processes to explain the distribution limits of organisms whose range does not extend to their apparent physiological limits. Den Boer (1979) argues, from extensive trapping of carabid beetles 
in the Netherlands, that extinction and recolonization is the decisive factor in the population dynamics of the species he studied. The explanation of the maintenance of the $t$-allele system in house mice produced by Lewontin and Dunn (1960) also rests on a population structure of small demes, frequently dying out. Greaves and Rennison's (1973) explanation for the fast movement of Warfarin resistance outward from its point of origin invokes a very fluid population model with more in common with that suggested here than the classical view. Thus, it seems that new population dynamic models may help us to understand a variety of otherwise puzzling phenomena. Whether this includes the data presented in this paper must await further study.

Acknowledgements.-This work was begun during the tenure of a NERC studentship. Latterly I was supported by a University of East Anglia graduate studentship. I would like to thank Dr G. M. Hewitt for access to unpublished raw data and discussions, and M. C. Thornton and Dr H. Fletcher for discussion. The Elveden estates and the Ministry of Defence kindly gave permission for me to collect on their land. The U.K. Meteorological Office provided the Crown Copyright climatic data used in the discussion, and gave permission for their use.

\section{REFERENCES}

AIKMAN. D. AND HEWITT, G. M. 1972. An experimental investigation of the rate and form of dispersal in grasshoppers. J. Appl. Ecol., 9, 807-819.

BARTON, N. H. AND HEWITT, G. M. 1980. Hybrid zones and speciation. In Atchley, W. and Woodruff, D. S. (eds.) Essays on Evolution and Speciation in Honour of M. J. D. White, Cambridge University Press.

CARTER, R. N. AND PRINCE, S. D. 1981. Epidemic models used to explain biogeographical distribution limits. Nature, 293, 644-645.

DEN BOER, P. J. 1979. The significance of dispersal power for the survival of species with special reference to the carabid beetles in a cultivated countryside. In Halbach, $U$. and Jacobs, J. (eds.) Population Ecology, (Fortschr. Zool. 25(2/3)), Gustav Fischer, Stuttgart.

ENDLER, J. A. 1977. Geographic Variation, Speciation and Clines. Princeton Univ. Press.

FISHER, R. A. 1937. The wave of advance of an advantageous gene. Ann. Eugen., 7, 355-369.

GREAVES, J. H. AND RENNISON, B. D. 1973. Population aspects of warfarin resistance in the Brown Rat. Mammal Rev., 3, 27-29.

HADELER, K. P. 1976. Travelling population fronts. In Karlin, S. and Nevo, E. (eds.) Population Genetics and Ecology, Academic Press, London.

HARTLEY, D. J. AND BISHOP, J. A. 1979. Home range and movement in populations of Rattus norvegicus polymorphic for warfarin resistance. Biol. J. Linn. Soc., 12, 19-43.

HEWITT, G. M. 1973. The integration of supernumerary chromosomes into the Orthopteran genome. Cold Spring Harbour Symp. Quant. Biol., 38, 183-194.

HEWITT, G. M. 1976. Meiotic drive for B-chromosomes in the primary oocytes of Myrmeleotettix maculatus (Orthoptera: acrididae) Chromosoma, 56, 381-391.

HEWITT, G. M. AND BROWN, F. M. 1970. The B-chromosome system of Myrmeleotettix maculatus. V. A steep cline in East Anglia. Heredity, 25, 363-371.

JONES, N. 1975. B-chromosome systems in flowering plants and animal species. Int. Rev. Cytol., 40, 1-100.

KIMURA, M. AND WEISS, G. H. 1964. The stepping stone model of population structure and the decrease of genetic correlation with distance. Genetics, 49, 561-576.

LEES, D. R. 1981. Industrial melanism: genetic adaptation of animals to air pollution. In Bishop, J. A. and Cook, L. M. (eds.) Genetic Consequences of Man-Made Changes, Academic Press, London, pp. 129-176.

LEWONTIN, R. C. AND DUNN, L. C. 1960. The evolutionary dynamics of a polymorphism in the house mouse. Genetics, 45, 705-722.

MAY, R. M., ENDLER, J. A. AND MCMURTRIE, R. E. 1975. Gene frequency clines in the presence of selection opposed by gene flow. Am. Nat., 109, 659-676. 
RAMEL, C. 1980. A B-chromosome system of Myrmeleotettix maculatus (Thunb.) (Orthoptera: Acrididae) in Sweden. Hereditas, 92, 309-313.

ROBINSON, P. M. 1973. The ecological genetics of the polymorphism for B-chromosomes in the grasshopper Myrmeleotettix maculatus (Thunb.) (Orthoptera: Acrididae). Ph.D. thesis, Univ. of East Anglia.

ROBINSON, P. M. AND HEWITT, G. M. 1976. Annual cycles in the incidence of B-chromosones in the grasshopper Myrmeleotettix maculatus (Acrididae: Orthoptera). Heredity, 36, $399-412$.

SHAW, M. W. 1981. A B-chromosome cline in the mottled grasshopper. Ph.D. thesis, Univ. of East Anglia.

SLATKIN, M. 1976. The rate of spread of an advantageous allele in a subdivided population. In Karlin, S. and Nevo, E. (eds.) Population genetics and ecology, Academic Press, London.

SLATKIN, M. AND CHARLESWORTH, D. 1978. The spatial distribution of transient alleles in a subdivided population: a simulation study. Genetics, $89,793-810$.

SNEDECOR, G. W. AND COCHRAN, W. G. 1963. Statistical Methods, 6th ed., Iowa State Univ. Press, Ames, Iowa.

WUNDERLE, J. M. 1981. An analysis of a morph-ratio cline in the Bananaquit (Coeroba flaveola) in Granada, W. Indies. Evolution, 35, 333-344. 